Плодоводство и виноградарство Юга России № 66(6), 2020 г.

УДК 634.8: 631.52

DOI 10.30679/2219-5335-2020-6-66-48-58
АГРОБИОЛОГИЧЕСКАЯ

И УВОЛОГИЧЕСКАЯ

ХАРАКТЕРИСТИКА НОВЫХ СОРТОВ

ВИНОГРАДА СЕЛЕКЦИИ

ГЕРМАНИИ И РОССИИ

В АГРОЭКОЛОГИЧЕСКИХ

УСЛОВИЯХ ЗАПАДНОГО

ПРЕДКАВКАЗЬЯ

Дергачёв Дмитрий Владимирович

канд. с.-х. наук.

Директор

Ларькина Марина Дмитриевна

канд. с.-х. наук.

зам. директора по науке

ООО «Инноваџионная Компания

«Таманский Биотехнологический Центр»,

Темрюк, Краснодарский край, Россия

e-mail: maran-1@yandex.ru

Петров Валерий Семёнович

д-р с.-х. наук

руководитель научного направления

ведущий научный сотрудник

лаборатории управления

воспроизводством в ампелоценозах

и экосистемах

e-mail: petrov_53@mail.ru

Панкин Михаил Иванович

д-р с.-х. наук

ведущий научный сотрудник

лаборатории управления

воспроизводством в ампелоценозах

и экосистемах

e-mail: PankinMI@mail.ru

Цику Дамир Муратович

аспирант,

мл. научный сотрудник

лаборатории управления

воспроизводством в ампелоценозах

и экосистемах

e-mail: $\underline{\text { mr.tsiku@mail.ru }}$

Марморштейн Анна Александровна аспирант,

младший научный сотрудник

лаборатории управления

воспроизводством в ампелоценозах

и экосистемах

e-mail: am342@yandex.ru
UDC 634.8: 631.52

DOI 10.30679/2219-5335-2020-6-66-48-58

\section{AGRIBIOLOGICAL AND UOLOGICAL CHARACTERISTICS OF NEW GRAPE VARIETIES OF GERMANY AND RUSSIA BREEDING UNDER THE AGROECOLOGY CONDITIONS OF THE WESTERN SISCAUCASIA}

Dergachev Dmitriy Vladimirovich Cand. Agr. Sci.

Director

Larkina Marina Dmitrievna

Cand. Agr. Sci.

Deputy Chief for Science

«Innovation Company

«Taman Biotechnology Center» LLC, Temryuk, Krasnodar Region, Russia e-mail:maran-1@yandex.ru

Petrov Valeriy Semionovich Dr. Sci. Agr.

Head of Scientific Direction

Leading Research Associate of Reproduction Control in the Ampelocenoses and Ecological systems Laboratory e-mail: petrov_53@mail.ru

Pankin Mikhail Ivanovich

Dr. Sci. Agr.

Leading Research Associate of Reproduction Control in the Ampelocenoses and Ecological systems Laboratory e-mail: PankinMI@mail.ru

Tsiku Damir Muratovich Postgraduate,

Junior Research Associate of Reproduction Control in the Ampelocenoses and Ecological systems Laboratory e-mail: mr.tsiku@mail.ru

Marmorshtein Anna Aleksandrovna Postgraduate, Junior Research Associate of Laboratory of Reproduction in the Ampelocenosis and Ecological Systems e-mail: am342@yandex.ru 
Плодоводство и виноградарство Юга России № 66(6), 2020 г.

Митрофанова Екатерина Александровна
канд. с.-х. наук
старший научный сотрудник
НЦ «Виноделие»
e-mail: skripka58@ mail.ru

Федеральное государственное бюджетное научное учреждение «Северо-Кавказский федеральный научный иентр садоводства, виноградарства, виноделия», Краснодар, Россия

В данной работе представлены результаты агробиологической и увологической оценки новых сортов винограда селекции Германии и России, произрастающих в агроэкологических условиях Западного Предкавказья. Исследования были выполнены с использованием современных методов полевых исследований, принятых в виноградарстве, в нетипичных погодных условиях 2019 года. В качестве объекта изучения были взяты сорт немецкого происхождения Монарх и отечественный гибрид Подарок Дмитрия. Данные технические формы были выбраны для исследования, поскольку они отличаются высокими биологическими показателями и дают хороший урожай ягод винограда даже в неблагоприятные для их возделывания годы. Кроме того, они обладают признаками устойчивости к биотическим и абиотическим стрессорам, характерным для неустойчивого и стрессового климата Западного Предкавказья. В нестабильных погодных условиях 2019 года в Черноморской зоне по основным показателям продуктивности нами была проведена агробиологическая и увологическая оценка интродуцированного немецкого сорта Монарх и отечественного перспективного гибрида Подарок Дмитрия, на фоне контроля, которым выступал отечественный сорт винограда Саперави северный. Результаты проведенной оценки показали, что изучаемые объекты проявляли высокие агробиологические показатели в стрессовых погодно-климатических условиях зоны возделывания - Западного Предкавказья. Для этих же условий была проведена увологическая оценка гроздей изучаемых форм. Полученные в процессе выполнения нами указанных исследований данные следует рассматривать как предварительные, применительно к нетипичным агроэкологическим условиям 2019 года.

В целях получения более глубоких
Mitrofanova Ekaterina Aleksandrovna Cand. Agr. Sci.

Senior Research Associate of CS «Wine-making» e-mail:skripka58@mail.ru

Федеральное государственное бюджетное научное учреждение «Северо-Кавказский федеральный научный иентр садоводства, виноградарства, виноделия», Краснодар, Россия

This paper presents the results of agrobiological and uvological assessment of new grape varieties of breeding in Germany and Russia cultivated under the agro-ecological conditions of the Western Ciscaucasia. The studies were carried out using modern field research methods for viticulture in atypical weather c onditions in 2019. As an object of research, a grape variety of German origin Monarch and a domestic hybrid Gift of Dmitry, were used.

These technical forms were selected for research as they are characterized by high biological indicators, and give a good harvest of grape berries even in adverse years for their cultivation. Also they have signs of resistance to biotic and abiotic stressors typical for the unstable and stressful climate of the Western Ciscaucasia.

Under the unstable weather conditions of 2019, in the Black Sea zone, according to the main indicators of productivity, an agrobiological and uvological assessment of the introduced German Monarch variety and the domestic promising hybrid Dmitriy Podarok was carried out against the background of control of the domestic Saperavi Severny grape variety. The results of assessment carried out by us showed that the studied objects indicated high agrobiological indexes under stressful climatic conditions of Western Siscaucasia zone. For the same conditions, a uvological assessment of the bunches of the studied forms was carried out. The data obtained by us in the process of these research should be considered as preliminary data in relation to the atypical agroecological conditions of 2019. To get the deeper 
Плодоводство и виноградарство Юга России № 66(6), 2020 г.

и обоснованных выводов исследования в данном направлении будут продолжены.

Ключевые слова: ВИНОГРАД, СОРТ, АГРОБИОЛОГИЧЕСКИЕ ПОКАЗАТЕЛИ, УВОЛОГИЧЕСКАЯ ОЦЕНКА and well based conclusions, research in this field will be continued.

Key words: GRAPES, VARIETY, AGROBIOLOGICAL INDICATORS, UVOLOGICAL ESTIMATION

Введение. В современных российских насаждениях винограда существует острый дефицит технических сортов отечественной селекции с положительными признаками для практического использования. В Государственном реестре селекционных достижений Российской Федерации зарегистрировано 272 сорта винограда, допущенных к использованию в производстве, в том числе технических - 136 наименований.

Наибольшую площадь (1000 га и более) занимают сорта Алиготе, Бианка, Каберне-Совиньон, Мерло, Первенец Магарача, Шардоне и другие. В промышленных насаждениях Краснодарского края на долю наиболее распространенных сортов приходится около 70 \% площади насаждений от их общей территории. Доминируют преимущественно сорта западноевропейской селекции. Доля других сортов, автохтонных и отечественной селекции, составляет менее $1 \%$ каждого генотипа [1-8].

Дефицит отечественных сортов и доминирование интродуцированных в насаждениях винограда сопровождается недостаточной агробиологической и экологической устойчивостью ампелоценозов, повышенной восприимчивостью европейских сортов к биотическим и абиотическим стрессорам. Восприимчивость сопровождается усложнением агротехнологий, повышением химического прессинга, нарушением экологии, ухудшением качества пищевой продукции. У используемых сортов неоправданно низкий уровень реализации потенциала хозяйственной продуктивности винограда, в среднем 60 \% по Краснодарскому краю, в других регионах ещё меньше. Сортимент разбалансирован по срокам созревания.

Малая доля технических сортов раннего, раннесреднего и среднего сроков созревания сужает конвейер поставок винограда, затрудняет организацию процесса переработки [9-13]. В современных условиях интеграции российской 
Плодоводство и виноградарство Юга России № 66(6), 2020 г.

экономики в мировой рынок и нарастании конкуренции, а также в связи с изменчивостью климата возрастает потребность в устойчивых и высоко адаптивных сортах для создания конкурентоспособного виноградарства [14-16].

Цель настоящих исследований - изучение и выделение новых сортов винограда, конкурентоспособных по хозяйственно ценным и биологическим признакам в нестабильных агроэкологических условиях юга России.

Объекты и методы исследований. В качестве объекта исследований использовали технический сорт винограда Монарх, интродуцированный из Германии, и новый отечественный генотип универсального направления использования Подарок Дмитрия. В качестве контроля применяли отечественный сорт Саперави северный. Кусты винограда на участке исследований посажены с учетом силы роста растений: по схеме $3 \times 3$ м сорт Монарх и $3 \times 2$ м сорта Подарок Дмитрия и Саперави северный. Их изучение было проведено в агроэкологических условиях черноморской зоны виноградарства, в Темрюкском районе Краснодарского края, х. Белый. По классификации Б.П. Алисова район Темрюка относится к умеренному климатическому поясу атлантико-континентальной европейской области [17-26].

Обсуждение результатов. На участке исследований погодные условия характеризуются нестабильным температурным режимом и неравномерным выпадением атмосферных осадков. Средняя температура воздуха за год, по средним данным за многолетний период с 1989 по 2018 гг., составляет $+12{ }^{\circ} \mathrm{C}$, средний абсолютный максимум $-+35^{\circ} \mathrm{C}$, средний абсолютный минимум равен $-14{ }^{\circ} \mathrm{C}$. За данный тридцатилетний период температура воздуха опускалась до $-24{ }^{\circ} \mathrm{C}$ в январе 2006 года и поднималась до $+38^{\circ} \mathrm{C}$ в августе 2005 и 2007 гг. Среднегодовое количество атмосферных осадков равно 544 мм. Половина осадков выпадает в период с температурами воздуха выше $+10^{\circ} \mathrm{C}$ (апрель-октябрь). Однако по значениям летнего ГТК из-за высоких летних температур район относится к зоне сухого земледелия, где высок риск засух [27]. 
Плодоводство и виноградарство Юга России № 66(6), 2020 г.

Метеорологические условия в год исследования сортов винограда (2019) были более теплыми и сухими, чем за последние тридцать лет - среднегодовая температура была на $1{ }^{\circ} \mathrm{C}$ выше, сумма атмосферных осадков на 150 мм меньше. Минимум температуры был отмечен в феврале и составил $-6^{\circ} \mathrm{C}$, максимум - во вторую и третью декаду августа, $+34{ }^{\circ} \mathrm{C}$. За исключением июля, августа и сентября, среднемесячная температура воздуха была выше аналогичных показателей за период 1989-2018 гг. (рис. 1).

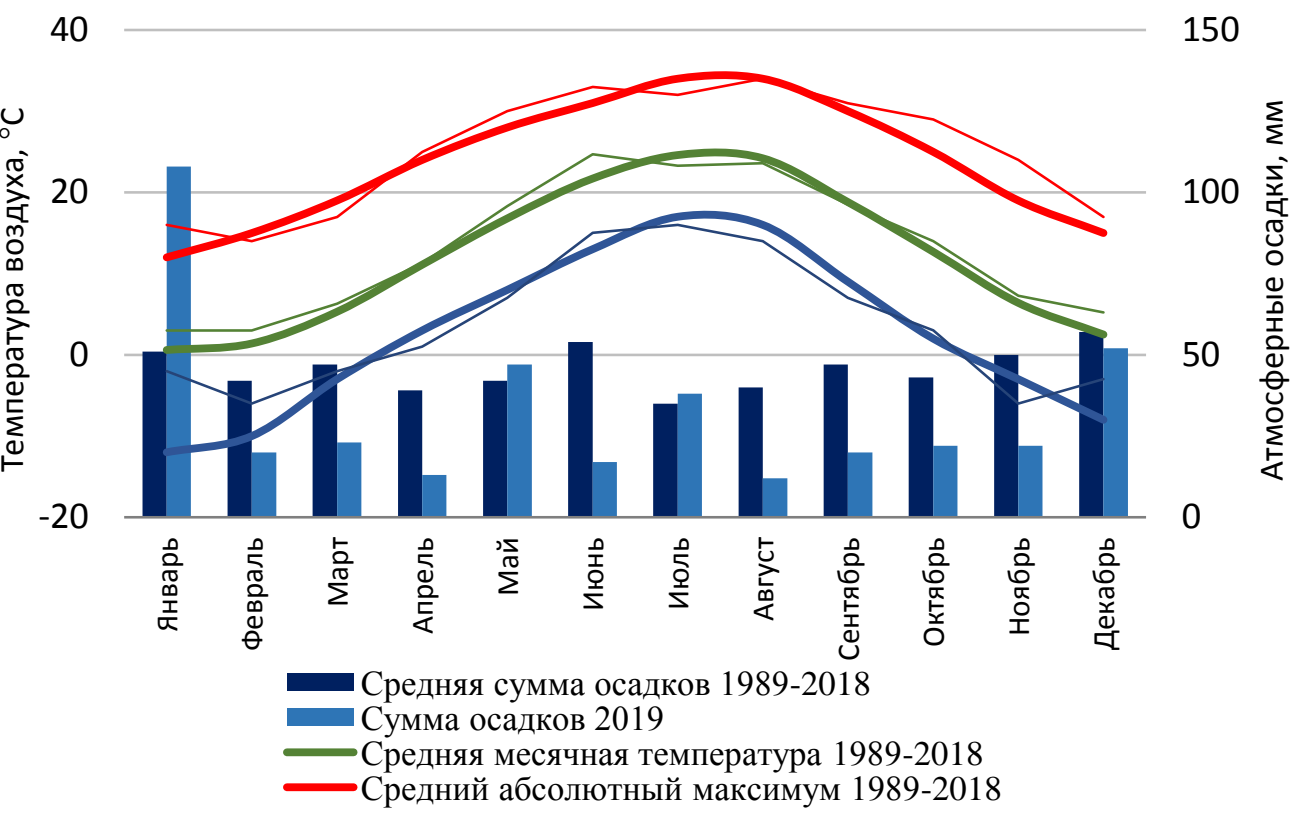

Рис. 1. Погодно-климатические условия на участке изучения сортов винограда, по данным метеостанции г. Темрюка

В сложившихся погодных условиях по положительным хозяйственно ценным признакам выделялся сорт винограда Монарх. У данного сорта показатели коэффициентов плодоношения и плодоносности, масса гроздей и урожайность были выше, чем у контроля. Коэффициент плодоношения превосходил контрольный показатель на 0,17 , плодоносности - на 0,14 единиц. Наименьшая существенная разница $\left(\mathrm{HCP}_{05}\right)$ по Б.А. Доспехову была несущественна - на 0,5 процентном уровне значимости. Средняя масса грозди была выше, чем на контроле, в 1,26 раза и составляла 261 г. $\mathrm{HCP}_{05}$ была существенна. По массе гроздей с одного куста сорт Монарх превосходил контрольный сорт Саперави северный практически в два раза. Урожайность с единицы 
Плодоводство и виноградарство Юга России № 66(6), 2020 г.

площади была равна 24,94 т/га, что на 5,63 т/га выше, чем на контрольном сорте. $\mathrm{HCP}_{05}$ была существенна.

У сорта винограда Подарок Дмитрия коэффициенты плодоношения и плодоносности по сравнению с сортом Монарх были ниже, отличия несущественны. Масса грозди была выше, чем у контрольного сорта, на 39 г и меньше, чем у сорта Монарх, на 15 г и составляла 246 г. Урожайность винограда Подарок Дмитрия была ниже, чем у контрольного Саперави северного и сорта Монарх, на 26 и 42 \% соответственно. НСР 05 по массе гроздей и урожайности винограда была существенна.

Исходя из полученных данных в агроэкологических условиях 2019 года, можно сделать вывод, что сорт винограда Монарх превосходил контрольный Саперави Северный по всем значимым агробиологическим показателям. Сорт Подарок Дмитрия показал лучшие результаты относительно контроля только по средней массе гроздей. По остальным хозяйственно ценным признакам данный сорт уступал контрольному сорту Саперави северный (табл. 1).

Таблица 1 - Агробиологические показатели изучаемых сортов винограда, х. Белый, Краснодарский край, 2019 г.

\begin{tabular}{|c|c|c|c|c|c|c|c|c|c|}
\hline$e^{2}$ & 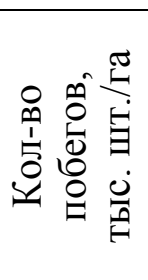 & 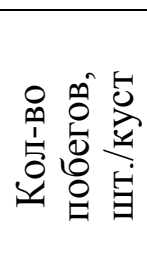 & 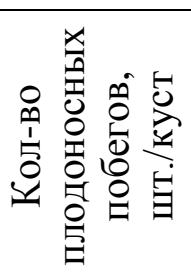 & 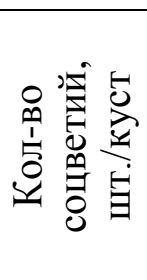 & $\bar{\Delta}$ & $\mathscr{V}$ & 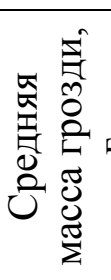 & 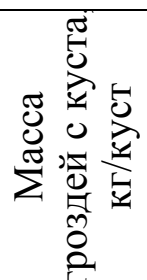 & 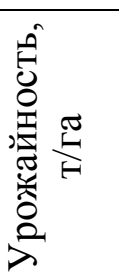 \\
\hline $\begin{array}{l}\text { Подарок } \\
\text { Дмитрия }\end{array}$ & 65 & 39 & 22 & 35 & 0,90 & 1,59 & 246 & 8,6 & 14,34 \\
\hline Монарх & 91 & 82 & 52 & 86 & 1,05 & 1,65 & 261 & 22,4 & 24,94 \\
\hline $\begin{array}{l}\text { Саперави } \\
\text { северный } \\
\text { (контроль) }\end{array}$ & 107 & 64 & 37 & 56 & 0,88 & 1,51 & 207 & 11,6 & 19,31 \\
\hline $\mathrm{HCP}$ & & 2,7 & 2,2 & 2,9 & 0,22 & 0,2 & 4,3 & 4,94 & 4,21 \\
\hline
\end{tabular}

По комплексу увологических показателей среди изучаемых выделяется сорт Монарх: он превосходит сорт Подарок Дмитрия и контроль Саперави северный по массе грозди (Монарх - 261 г, Подарок Дмитрия - 246 г, Саперави 
Плодоводство и виноградарство Юга России № 66(6), 2020 г.

северный - 207 г). Преимущество также отмечено по количеству ягод в грозди: у сорта Монарх их было больше, чем у Подарка Дмитрия, в 1,97 раза и чем у Саперави северного - в 1,14 раза.

Сорт Монарх положительно выделяется по долевому соотношению веса ягод в грозди и минимальному содержанию гребней. У сорта Подарок Дмитрия эти показатели практически одинаковы с контролем. Кожица ягод у сорта Монарх тонкая и занимает небольшую часть. На 100 г ягод её доля составляет 16 г, в тоже время у сорта Подарок Дмитрия 38 г, у Саперави северного 17 г (табл. 2).

Таблица 2 - Увологические показатели гроздей изучаемых сортов винограда, Краснодарский край, х. Белый, 2019 г.

\begin{tabular}{|c|c|c|c|c|}
\hline \multicolumn{2}{|l|}{ Показатель } & Монарх & $\begin{array}{l}\text { Подарок } \\
\text { Дмитрия }\end{array}$ & $\begin{array}{l}\text { Саперави } \\
\text { северный }\end{array}$ \\
\hline \multicolumn{2}{|l|}{ Вес грозди, г } & 261 & 246 & 207 \\
\hline \multicolumn{2}{|l|}{ Длина грозди, см } & 17,3 & 18 & 18,4 \\
\hline \multicolumn{2}{|l|}{ Ширина грозди, см } & 10,8 & 11,5 & 13 \\
\hline \multicolumn{2}{|c|}{ Число ягод в грозди, шт. } & 184 & 93 & 161 \\
\hline \multirow{2}{*}{ Вес ягод в грозди } & $\Gamma$ & 258 & 203 & 203 \\
\hline & $\%$ & 98,9 & 98 & 98 \\
\hline \multirow{2}{*}{ Вес гребней } & $\Gamma$ & 2,9 & 4,2 & 4,2 \\
\hline & $\%$ & 1,1 & 2 & 2 \\
\hline \multicolumn{2}{|c|}{ Отношение веса ягод к весу гребня, \% } & 1,1 & 3,8 & 2,1 \\
\hline \multicolumn{2}{|c|}{ Число ягод на 100 г грозди } & 71 & 38 & 78 \\
\hline \multicolumn{2}{|c|}{ Вес кожицы в грозди, г } & 29,9 & 35,5 & 28 \\
\hline \multicolumn{2}{|c|}{ Вес мякоти в грозди, г } & 208 & 168 & 163 \\
\hline \multicolumn{2}{|c|}{ Вес семян в грозди, г } & 6,7 & 0,7 & 5,5 \\
\hline \multicolumn{2}{|c|}{ Вес 100 семян, Г } & 3 & 1,5 & 2,4 \\
\hline \multicolumn{2}{|c|}{ Число семян в грозди, шт. } & 223 & 45,5 & 234 \\
\hline \multicolumn{2}{|c|}{ Число семян в ягодах, шт. } & 1,2 & 0,5 & 1,4 \\
\hline \multicolumn{2}{|c|}{ Ср. масса 100 ягод } & 140 & 218 & 126 \\
\hline \multicolumn{2}{|c|}{ Ср. вес кожицы в 100 ягодах } & 16 & 38 & 17 \\
\hline \multicolumn{2}{|c|}{ Ср. вес семян в 100 ягодах } & 3,7 & 0,8 & 3,4 \\
\hline \multicolumn{2}{|c|}{ Ср. вес мякоти в 100 ягодах } & 113 & 180 & 101 \\
\hline \multicolumn{2}{|c|}{ Сахар, г/дм3 } & 23,2 & 23,1 & 22,2 \\
\hline \multicolumn{2}{|l|}{ ГАП } & 2,4 & 3 & 2,5 \\
\hline
\end{tabular}


Плодоводство и виноградарство Юга России № 66(6), 2020 г.

Сорт Подарок Дмитрия положительно выделяется по наименышему количеству и весу семян в ягодах винограда. Средний вес семян в 100 ягодах винограда у него был наименьший - 0,8 г (у сортов Монарх и Саперави северный соответственно 3,7 и 3,4 г). Это дает нам основание утверждать, что данный сорт можно практически считать бессемянным. Также сорт Подарок Дмитрия обладал в изучаемый год наибольшей массой 100 ягод. По этому показателю он превосходил сорт Монарх в 1,56 раза и Саперави северный в 1,73 раза.

По показателю сахаристости сорта Подарок Дмитрия и Монарх практически не отличались $\left(23,1\right.$ г/дм ${ }^{3}$ и 23,2 г/дм³ соответственно). У контрольного сорта Саперави северный сахаристость была наименьшей $(22,2$ г/дм³ $)$. У технических сортов винограда одним из важнейших является глюкоацидометрический показатель (ГАП). Устанавливается он для определения зрелости ягод винограда и наилучшего времени его сбора. Он изменяется в зависимости от динамики сахаристости и кислотности сока ягод по мере их созревания.

По показателю ГАП сорта винограда Монарх и Подарок Дмитрия существенно не различались и обладали близкими показателями $-2,4$ и 3,0 соответственно, в то время как контроль (Саперави Северный) значительно опередил изучаемые сорта.

Заключение. В агроэкологических условиях 2019 года сорт винограда Монарх значительно превзошел по ряду показателей сорта Подарок Дмитрия и Саперави северный. Однако сорт Подарок Дмитрия положительно выделился массой мякоти и ничтожным количеством семян в ягодах. Для объективной оценки данных сортов требуется их дальнейшее изучение в годы с различными температурными и водными режимами.

\section{Литература}

1. Виноградарство и виноделие в Краснодарском крае // Винорус Винотех. 2012. [Электронный ресурс] Режим доступа. URL: http://www.vinorus.ru/home/ winegrowing.aspx (дата обращения 10.01.2020). 
Плодоводство и виноградарство Юга России № 66(6), 2020 г.

2. Буйвал Р.А. Тихомирова Н.А. Сравнительный анализ потенциальной плодоносности сортов винограда в хозяйствах южного берега Крыма // Русский виноград. 2017. № 5. C. 166-174. S. $410-414$.

3. Ollig W. Tafeltrauben - eine neue Obstart // Obstbau - 2003. - Jg.28, N 8. -

4. Егоров Е.А., Серпуховитина К.А., Петров В.С. Состояние и перспективы научного обеспечения устойчивого развития виноградарства // Виноделие и виноградарство. 2008. № 3. C. 6-8.

5. Ganter B. Kleinterrassen wie bewirtschaften? // Bad.Winzer. - 2009. - N 3. P. 33-35

6. Агрометеорологические бюллетени по территории Краснодарского края / Краснодар: Краснодарский краевой центр по гидрометеорологии и мониторингу окружающей среды. 1989-2019. с. 5.

7. Петров В.С., Павлюкова Т.П., Талаш А.И. Научные основы устойчивого выращивания винограда в аномальных погодных условиях. Краснодар: ГНУ СКЗНИИСиВ, 2014. 157 c.

8. López-Miranda S., Yuste J., Lissarrague J.R. Effects of bearing unit, spur or cane, on yield components and bud productivity. Vitis, 2004, 43(1): 47-48.

9. Цику Д.М., Гусев С.Э., Пята Е.Г., Петров В.С. Эмбриональная плодоносность столовых сортов винограда в острозасушливых условиях Волгоградской области [Электронный ресурс] // Плодоводство и виноградарство Юга России. 2019. № 56(2). С. 133-143. URL: http://journalkubansad.ru/pdf/19/02/12.pdf. DOI: 10.30679/2219-5335-2019-2-56-133-143 (дата обращения: 09.10.2020).

10. Влияние способов содержания почвы на эмбриональную плодоносность почек и фитосанитарное состояние винограда / В.С. Петров [и др. ] // Виноделие и виноградарство. 2005. № 3. C. 42.

11. Spring J. - L., Ferretti M. Influence du rendement sur la qualite des raisins et des vins de Carminoir cultive au Tessin // Rev.suisse Vitic.Arboric.Hortic. - 2007. - vol. 39, N 6.-P.361364. - Bibliogr.: p.363.

12. Vingione M., Meglioraldi S. La carica di gemme ottimale per Ancellota e Lambruschi // inform.agr. - 2007. - N 3.-P.69-73

13. Современные методологические аспекты организации селекционного процесса в садоводстве и виноградарстве / Е.А. Егоров [и др.]. Краснодар: СКЗНИИСиВ, 2012. 569 с.

14. Ключникова, Г.Н. Закономерности роста и плодоношения внутривидовых и межвидовых сортов винограда в зоне неукрывной культуры: автореф. дис. ... канд. с.-х. наук : 06.01.07 / Ключникова Галина Николаевна. Краснодар, 2002. 48 с.

15. Никулушкина Г.Е., Ларькина М.Д. Высококачественные столовые сорта селекции АЗОСВиВ - Маринка, Черномор анапский и их особенности // Виноградарство и виноделие. 2015, Ялта. Том XLV. С. 15-17.

16. Столовые сорта винограда раннего срока созревания / А.И. Жуков [и др.]. // Сорта винограда Анапской зональной опытной станции виноградарства и виноделия. Методические рекомендации. Краснодар, 2012. С. 6-9.

17. Виноградарство и виноделие на Кубани: обзор рынка//Деловая газета Юг. - 2007. - [Электронный ресурс] — Режим доступа. — URL: http://www. dgyug.ru/a/2007/10/23/Vinogradarstvo_i_vinodeli?readcomment=1 (дата обращения 10.01.2020).

18. Ларькина М.Д., Никулушкина Г.Е., Щербаков С.В. Перспективные столовые сорта винограда селекции АЗОСВиВ, устойчивые к милдью // Виноделие и виноградарство. 2010. № 4. С. 31.

19. Амирджанов А.Г., Сулейманов Д.С. Оценка продуктивности сортов винограда и виноградников: методические указания. Баку, 1986. 56 с. 
Плодоводство и виноградарство Юга России № 66(6), 2020 г.

20. Петров В.С. Потенциал хозяйственной продуктивности винограда, его реализация в условиях умеренно континентального климата юга России // Магарач. Виноградарство и виноделие. 2016. № 1. С. 20-22.

21. Poenaru j. Cercetari privind relatii le dint e lungimea lastarilor, suprafata foliara, cantitatea si calitatea productici la vita de vie. -An. Inst/Cerc.Vitic.Vinif. Ploesti, 1974. -Vol. 5. P. 299 -313.

22. Annabi M., Houot S., Poitrenaud M., Rampon J.N., Gaillard H. Effect of organic amendments on soil aggregate stability. Sustainable Organic Waste Management for Environmental Protection and Food Safety. Ramiran 2004.1:51-54.

23. Luo G., Wu X., Leng P. Study on climatic zoning for wine-grape growing in Huabei Regions//Acta hortic. sinica. -2001. -Vol. 28, № 6. -P. 487-496. (Кит.).

24. Государственный реестр сортов винограда. [электронный ресурс] // URL:http://reestr.gossortrf.ru/reestr/culture/330.html (дата обращения: 11.02.2020)

25. Трошин Л.П., Радчевский П.П. Виноград иллюстрированный каталог // Мир садовода // Ростов-на-Дону, 2010. 271 с.

26. Пелях М.А. Справочник виноградаря. М.: Колос, 1971, 344 с.

27. Алисов Б.П. Географические типы климатов // Метеорология и гидрология. 1936. № 6.

\section{References}

1. Vinogradarstvo i vinodelie v Krasnodarskom krae // Vinorus Vinotekh. 2012. [Elektronnyj resurs] Rezhim dostupa. URL: http://www.vinorus.ru/home/ winegrowing.aspx (data obrashcheniya 10.01.2020).

2. Bujval R.A. Tihomirova N.A. Sravnitel'nyj analiz potencial'noj plodonosnosti sortov vinograda v hozyajstvah yuzhnogo berega Kryma // Russkij vinograd. 2017. № 5. S. 166-174.

3. Ollig W. Tafeltrauben - eine neue Obstart // Obstbau - 2003. - Jg.28, N 8. S. $410-414$.

4. Egorov E.A., Serpuhovitina K.A., Petrov V.S. Sostoyanie i perspektivy nauchnogo obespecheniya ustojchivogo razvitiya vinogradarstva // Vinodelie i vinogradarstvo. 2008. № 3. S. 6-8.

P. 33-35

5. Ganter B. Kleinterrassen wie bewirtschaften? // Bad.Winzer. - 2009. - N 3. -

6. Agrometeorologicheskie byulleteni po territorii Krasnodarskogo kraya / Krasnodar: Krasnodarskij kraevoj centr po gidrometeorologii i monitoringu okruzhayushchej sredy. 1989-2019. s. 5.

7. Petrov V.S., Pavlyukova T.P., Talash A.I. Nauchnye osnovy ustojchivogo vyrashchivaniya vinograda v anomal'nyh pogodnyh usloviyah. Krasnodar: GNU SKZNIISiV, 2014. 157 s.

8. López-Miranda S., Y uste J., Lissarrague J.R. Effects of bearing unit, spur or cane, on yield components and bud productivity. Vitis, 2004, 43(1): 47-48.

9. Ciku D.M., Gusev S.E., Pyata E.G., Petrov V.S. Embrional'naya plodonosnost' stolovyh sortov vinograda v ostrozasushlivyh usloviyah Volgogradskoj oblasti [Elek-tronnyj resurs] // Plodovodstvo i vinogradarstvo Yuga Rossii. 2019. № 56(2). S. 133-143. URL: http://journalkubansad.ru/pdf/19/02/12.pdf. DOI: 10.30679/2219-5335-2019-2-56-133-143 (data obrashcheniya: 09.10.2020).

10. Vliyanie sposobov soderzhaniya pochvy na embrional'nuyu plodonosnost' pochek i fitosanitarnoe sostoyanie vinograda / V.S. Petrov [i dr. ] // Vinodelie i vinogradarstvo. 2005. № 3. S. 42.

11. Spring J. - L., Ferretti M. Influence du rendement sur la qualite des raisins et des vins de Carminoir cultive au Tessin // Rev.suisse Vitic.Arboric.Hortic. - 2007. - vol. 39, N 6.P.361-364. - Bibliogr.: p.363. 
Плодоводство и виноградарство Юга России № 66(6), 2020 г.

12. Vingione M., Meglioraldi S. La carica di gemme ottimale per Ancellota e Lambruschi // inform.agr. - 2007. - N 3.-P.69-73

13. Sovremennye metodologicheskie aspekty organizacii selekcionnogo processa v sadovodstve i vinogradarstve / E.A. Egorov [i dr.]. Krasnodar: SKZNIISiV, 2012. 569 s.

14. Klyuchnikova, G.N. Zakonomernosti rosta i plodonosheniya vnutrividovyh i mezhvidovyh sortov vinograda $\mathrm{v}$ zone neukryvnoj kul'tury: avtoref. dis. ... kand. s.-h. nauk : 06.01.07 / Klyuchnikova Galina Nikolaevna. Krasnodar, 2002. 48 s.

15. Nikulushkina G.E., Lar'kina M.D. Vysokokachestvennye stolovye sorta selekcii AZOSViV - Marinka, Chernomor anapskij i ih osobennosti // Vinogradarstvo i vinodelie. 2015, Yalta. Tom XLV. S. 15-17.

16. Stolovye sorta vinograda rannego sroka sozrevaniya / A.I. Zhukov [i dr.]. // Sorta vinograda Anapskoj zonal'noj opytnoj stancii vinogradarstva i vinodeliya. Metodicheskie rekomendacii. Krasnodar, 2012. S. 6-9.

17. Vinogradarstvo i vinodelie na Kubani: obzor rynka // Delovaya gazeta Yug. 2007. [Elektronnyj resurs] Rezhim dostupa. URL: http://www. dgyug.ru/a/2007/10/23/Vinogradarstvo_i_vinodeli?readcomment=1 (data obrashcheniya 10.01.2020).

18. Lar'kina M.D., Nikulushkina G.E., Shcherbakov S.V. Perspektivnye stolovye sorta vinograda selekcii AZOSViV, ustojchivye k mild'yu // Vinodelie i vinogradarstvo. 2010. № 4. S. 31 .

19. Amirdzhanov A.G., Sulejmanov D.S. Ocenka produktivnosti sortov vinograda i vinogradnikov: metodicheskie ukazaniya. Baku, 1986. $56 \mathrm{~s}$.

20. Petrov V.S. Potencial hozyajstvennoj produktivnosti vinograda, ego realizaciya $\mathrm{v}$ usloviyah umerenno kontinental'nogo klimata yuga Rossii // Magarach. Vinogradarstvo i vinodelie. 2016. № 1. S. 20-22.

21. Poenaru j. Sercetari privind relatii le dint e lungimea lastarilor, suprafata foliara, cantitatea si calitatea productici la vita de vie. -An. Inst/Cerc.Vitic.Vinif. Ploesti, 1974. -Vol. 5. P. 299 -313.

22. Annabi M., Houot S., Poitrenaud M., Rampon J.N., Gaillard H. Effect of organic amendments on soil aggregate stability. Sustainable Organic Waste Management for Environmental Protection and Food Safety. Ramiran 2004.1:51-54.

23. Luo G., Wu X., Leng P. Study on climatic zoning for wine-grape growing in Huabei Regions//Acta hortic. sinica. -2001. -Vol. 28, № 6. -R. 487-496. (Kit.).

24. Gosudarstvennyj reestr sortov vinograda. [elektronnyj resurs] // URL:http://reestr.gossortrf.ru/reestr/culture/330.html (data obrashcheniya: 11.02.2020)

25. Troshin L.P., Radchevskij P.P. Vinograd illyustrirovannyj katalog // Mir sadovoda // Rostov-na-Donu, 2010. $271 \mathrm{~s}$.

26. Pelyah M.A. Spravochnik vinogradarya. M.: Kolos, 1971, 344 s.

27. Alisov B.P. Geograficheskie tipy klimatov // Meteorologiya i gidrologiya. 1936. № 6. 